\title{
Unstable cardiac injury complicated with septic shock-a challenge
}

Neha Garg ${ }^{1}$, Kapil Dev Soni ${ }^{2^{*}}$ and Richa Aggarwal ${ }^{2}$

\begin{abstract}
Background: Road traffic accident accounts for $70 \%$ to $80 \%$ of the blunt cardiac injury. The true incidence varies in the literature due to non-uniform criteria for diagnosis.

Case Presentation: Here, we describe the case of a young male presenting after blunt chest injury and hemodynamic instability. Initially, the patient had frequent episodes of arrhythmias and hypotension due to cardiac injury per se. However, he was stabilized by day 2. Subsequently, patient developed cellulitis followed by septic shock and succumbed to cellulitis on day 5 of injury.

Conclusion: Sepsis is difficult to be diagnosed and treated in the presence of cardiac injury. Myocardial depression has been found in sepsis, which contributes as an added comorbidity in an already compromised heart function. Sepsis also interferes with the diagnosis and follow-up of progress of blunt cardiac injury.
\end{abstract}

Keywords: Blunt cardiac injury, Sepsis, Myocardial depression, Troponin

\section{Background}

Road traffic accident accounts for $70 \%$ to $80 \%$ of the blunt cardiac injury [1]. But due to non-availability of fixed criteria for its diagnosis, its exact incidence cannot be quantified [2]. It is reported to range between $8 \%$ and $76 \%$ [3]. Sepsis superimposed on blunt cardiac injury not only makes diagnosis difficult but also worsens prognosis.

\section{Case presentation}

A 25-year-old male patient presented with a history of fall of a large stone on chest at a construction site followed by loss of consciousness and fall on back. On initial presentation, blood pressure (BP) was 60/ $36 \mathrm{mmHg}$ and pulse was 184 beats/min. He was immediately intubated and resuscitated with fluids and inotropes. The patient responded by stabilising BP to $110 / 60 \mathrm{mmHg}$. Bilateral intercostal drains were put. Contrast enhanced CT (CECT) chest showed mild pericardial fluid, fractured third rib, and bilateral hemopneumothorax. The patient also had grade 3 liver injury. The

\footnotetext{
* Correspondence: kdsoni111@gmail.com

${ }^{2}$ Division of Critical \& Intensive care, All India Institute of Medical Sciences,

Ansari Nagar East, Gautam Nagar, New Delhi 110029, India

Full list of author information is available at the end of the article
}

patient was shifted to the intensive care unit (ICU) for further management.

On arrival at the ICU, there was a sudden drop in BP with new onset arrhythmias. Electrical alternans was noted on electrocardiogram as well. 2D echocardiogram (Fig. 1) demonstrated mild to moderate pericardial fluid, regional wall motion abnormality, and low ejection fraction. Therefore, urgent pericardiocentesis was done, and BP improved marginally afterwards. The patient developed repeated episodes of atrial fibrillation (Fig. 2) and ventricular tachycardia with hemodynamic instability requiring frequent defibrillations. The patient became hemodynamically stable with control of arrhythmias within 2 days. CPK MB, troponin $\mathrm{T}$, and troponin I were found to be positive. Repeat echocardiography showed a decreased ejection fraction of $25 \%$ to $30 \%$.

On the third day after ICU stay, the patient developed cellulitis on the back and half of thigh with high grade fever episodes and new onset hemodynamic instability. Immediately, cultures (blood, urine, and tracheal) were sent and antibiotics were escalated. However, no organism could be isolated probably because antibiotics had been initiated empirically. Meanwhile, crystalloids were administered cautiously under echo guidance. However, the patient continued to deteriorate and succumbed to septic shock on the fifth day of injury. 

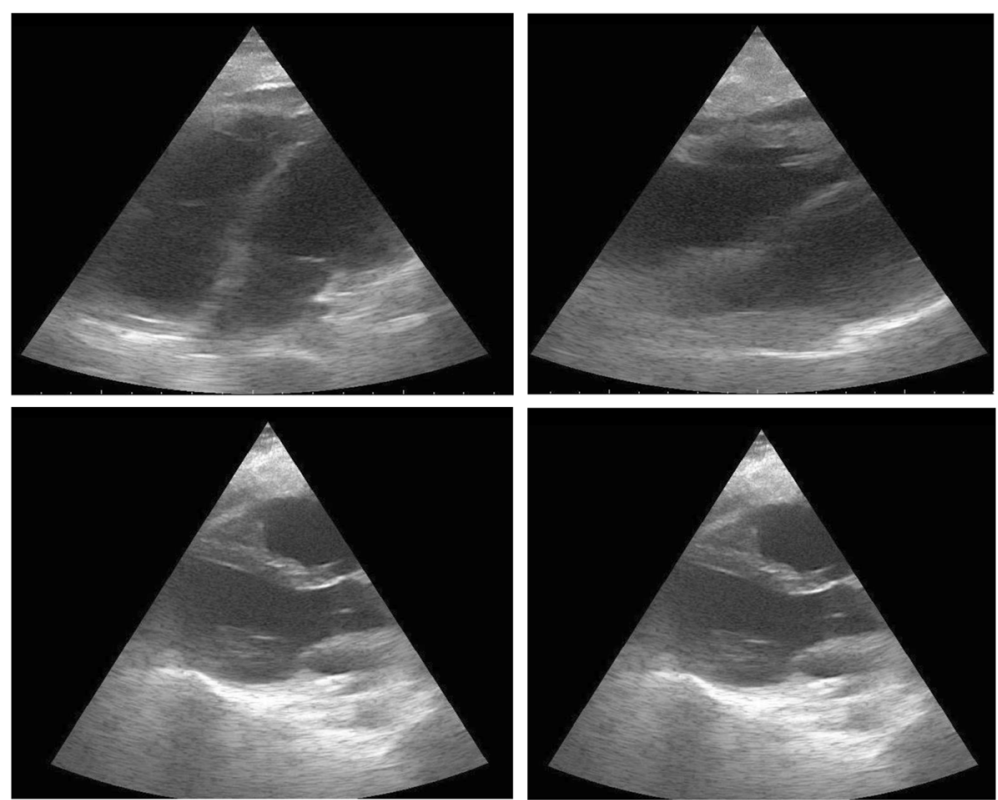

Fig. 1 Echocardiogram. Showing areas of regional wall motion abnormalities

Most patients with cardiac injury have fatal outcome before reaching the hospital. Penetrating cardiac injury, requirement of inotropes, and the presence of new onset arrhythmias are associated with worse survival. However, sepsis as a worse prognostic factor has not been reported previously. Here, we present a case where sepsis complicated the blunt cardiac injury and leads to fatal outcome.

Wijngaarden and associates et al. in their 10-year institutional review noted a $14 \%$ mortality in patients with blunt cardiac trauma which increased to $58 \%$ in patients requiring inotropic support [1]. The presence of arrhythmias decreases the survival to only $12 \%$ to $13 \%$ [4].

Blunt cardiac injury manifests with wide array of signs and symptoms varying from benign ectopic beats to fatal cardiac arrhythmias, shock leading to sudden collapse and death. It may also result in the rupture of the myocardium, pericardium, or valve assembly presenting with gross hemodynamic instability. The right ventricle is the most commonly to be injured portion of heart. However, subtle signs such as flail chest, ecchymosis, and sternal fractures may be the only presentation. Combined use of ECG and troponin I has been found to be one hundred percent sensitive for detection of clinically significant blunt chest trauma [5] (defined as cardiogenic shock, dysrhythmias requiring treatment, or structural cardiac abnormalities) [6]. A normal screening ECG rules out any significant cardiac injury and predicts a benign course [7]. However, troponin has also been found to be elevated in patients with septic shock
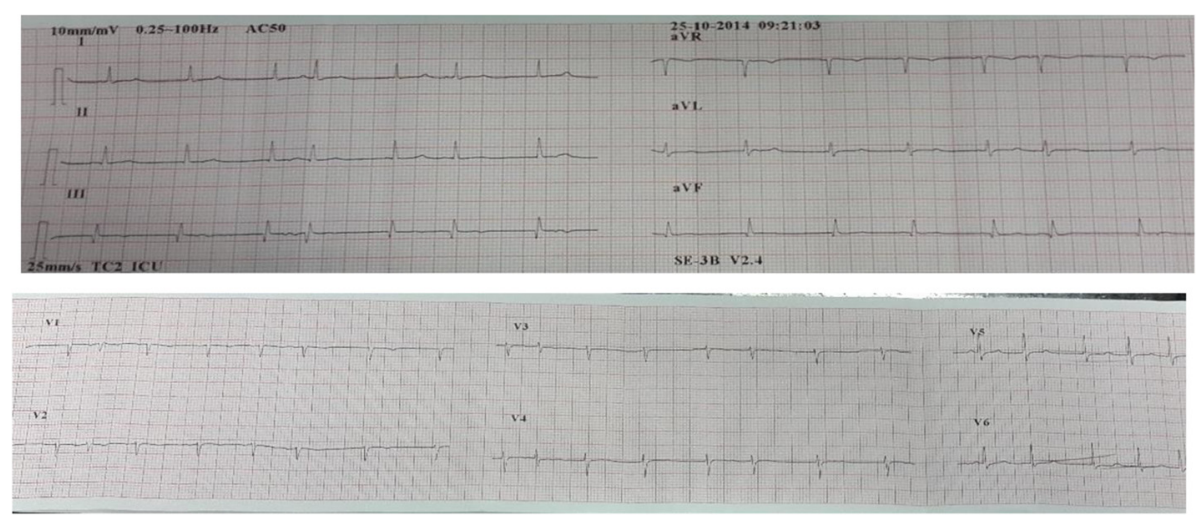

Fig. 2 Electrocardiogram. Showing the presence of atrial fibrillation 
Table 1 Inflammatory variables and tissue perfusion variables

\begin{tabular}{|c|c|}
\hline \multirow[t]{2}{*}{ Inflammatory variables ${ }^{a}$} & Fever $>38^{\circ} \mathrm{C}, \mathrm{TLC}-21,000$ \\
\hline & Heart rate greater than 100 \\
\hline \multirow[t]{2}{*}{ Tissue perfusion variables } & $\begin{array}{l}\text { BP } 60 / 40 \text { on receiving. "Improving } \\
\text { initially but increased ionotropic } \\
\text { support since } 3 \text { rd day. }\end{array}$ \\
\hline & $\begin{array}{l}\text { Urine output decreased on } 3 \mathrm{rd} \\
\text { day and became oliguric by } 4 \text { th day }\end{array}$ \\
\hline
\end{tabular}

${ }^{\mathrm{a}}$ The above variables can be due to trauma as well as systemic inflammatory response syndrome, the precursor of sepsis

"Sepsis added to it will cause hemodynamic instability which was already present in this patient thus confounding the presence of sepsis

TLC Total lymphocyte count; BP Blood pressure

making it unreliable for diagnosing in septic patients [8]. Echocardiography is an excellent tool for diagnosing and monitoring patient with blunt cardiac injury [9]. However, its interpretation becomes confounded by the presence of sepsis (Table 1).

Sepsis added to cardiac injury may lead to worse prognosis. Myocardial depression, in the form of biventricular dilation and decreased ejection fraction, has been demonstrated in most patients with septic shock [10]. This further complicates the management of patients with cardiac injury by acting as a "second hit" to the injured heart. This depression is however reversible over 7 to 10 days in survivors. End-diastolic dysfunction and end-systolic dysfunction are also found contributory to poor prognosis [11].

\section{Conclusions}

Early diagnosis and management of sepsis becomes the utmost priority in the presence of blunt cardiac injury. Signs and symptoms are often masked by cardiac injury leading to delayed diagnosis of sepsis. High index of suspicion and close monitoring is the key to identify the onset of severe sepsis. Probably an early initiation of antibiotics may help treat sepsis when it is masked by the presence of blunt cardiac injury. However, no recommendation can be made on the basis of a single case report, and the use of broad-spectrum antibiotics in blunt chest trauma in the absence of any definitive diagnosis may in fact lead to indiscriminate use of antibiotics and development of further resistant strains. Further studies are thus needed to identify markers of early sepsis in patients of blunt cardiac injury rather than blind antibiotic coverage in this group.

\section{Consent}

Written informed consent was obtained from the patient's parents for the publication of this report and the accompanying images.

\section{Abbreviations}

\%: percent; CECT: contrast enhanced CT; ECG: electrocardiogram;

ICU: intensive care unit.

\section{Competing interests}

The authors declare that they have no competing interests.

\section{Authors' contributions}

$\mathrm{NG}, \mathrm{KDS}$, and RA were involved in the treatment of the patient and data collection. NG and KDS were involved in writing the manuscript. All authors read and approved the final manuscript.

\section{Author details}

${ }^{1}$ Department of Anaesthesia and Intensive Care, All India Institute of Medical Sciences, Ansari Nagar East, Gautam Nagar, New Delhi 110029, India.

${ }^{2}$ Division of Critical \& Intensive care, All India Institute of Medical Sciences, Ansari Nagar East, Gautam Nagar, New Delhi 110029, India.

Received: 10 June 2015 Accepted: 25 March 2016

Published online: 08 April 2016

\section{References}

1. Wijngaarden MHV, Karmy JR, Talwar M, Simonetti V. Blunt cardiac injury: a 10 year institutional review. Injury. 1997;28:51-5.

2. Maenza RL, Seaberg D, D'Amico F. A meta-analysis of blunt cardiac trauma: ending myocardial confusion. Am J Emerg Med. 1996;14:237-41.

3. Feghali NT, Prisant LM. Blunt myocardial injury. Chest. 1995;108:1673-7.

4. Asensio JA, Berne JD, Demetriades D, Chan L, Murray J, Falabella A, et al. One hundred five penetrating cardiac injuries: a 2 year prospective evaluation. J Trauma. 1998:44:1973-82.

5. Salim A, Velmahos G, Jindal A, Chan L, Vassiliu P, Belzberg H, et al. Clinically significant blunt cardiac trauma: role of serum troponin levels combined with electrocardiographic findings. J Trauma. 2001;50:237-43.

6. Fernandez GM, Perez LJ, Castellano PN, Quero LF, Virgós-Lamela A, Otero-Ferreiro A, et al. Role of transesophageal echocardiography in the assessment of patients with blunt chest trauma: correlation of echocardiographic findings with the electrocardiogram and creatine kinase monoclonal antibody measurements. Am Heart J. 1998;135:476-81.

7. Velmahos GC, Karaiskakis M, Salim A, Toutouzas KG, Murray J, Asensio J, et al. Normal electrocardiography and serum troponin I levels preclude the presence of clinically significant blunt cardiac injury. J Trauma. 2003;54:45-51.

8. Mohammed AAO, Hussein SAA, Abdulrahman MAM. The clinic al significance of cardiac troponins in medical practice. J Saudi Heart Assoc. 2011;23:3-11.

9. Skorton DJ, Collins SM, Nichols J, Pandian NG, Bean JA, Kerber RE. Quantitative texture analysis in two-dimensional echocardiography: application to the diagnosis of experimental myocardial contusion. Circulation. 1983;68:217-23.

10. Krishnagopalan S, Kumar A, Parrillo JE, Kumar A. Myocardial dysfunction in the patient with sepsis. Curr Opin Crit Care. 2002:8:376-88.

11. Ashraf AO, Nader ES, Mahmoud MR. Cardiac functions in patients with sepsis and septic shock. Egyptian Heart J. 2012;64:191-6.

Submit your next manuscript to BioMed Central and we will help you at every step:

- We accept pre-submission inquiries

- Our selector tool helps you to find the most relevant journal

- We provide round the clock customer support

- Convenient online submission

- Thorough peer review

- Inclusion in PubMed and all major indexing services

- Maximum visibility for your research 